Gut, 1984, 25, 748-755

\title{
Detection of early neoplastic changes in experimentally induced colorectal cancer using scanning electron microscopy and cell kinetic studies
}

\author{
T COOKE, N KIRKHAM, D H STAINTHORP, C INMAN, \\ N GOETING, AND I TAYLOR
}

From the Departments of Surgery and Pathology, Faculty of Medicine, University of Southampton, Southampton

SUMmarY Colonic tumours were induced in Wistar rats using 12 consecutive subcutaneous injections of azoxymethane at a dose of $10 \mathrm{mg} / \mathrm{kg} / \mathrm{week}$. Pairs of rats were killed at five weekly intervals after initial injection until 25 weeks. Colonic mucosa was sampled from five standard areas along the length of the colon and examined by both scanning electron microscopy and conventional light microscopy. The crypt cell production rate was measured by stathmokinetic techniques. Scanning electron microscopy showed microadenomas as early as five weeks and consistently after 15 weeks. They were found predominantly in the distal colon and increased in size with time. The lesions showed a progressive increase in the number of crypts per adenoma and increasingly disorganised slit shaped crypt orifices. The presence of epithelial dysplasia in the microadenomas and of invasion of the colonic wall by carcinoma was confirmed histologically, although fewer lesions were identified in tissue sections than by scanning electron microscopy. Crypt cell production rate increased with time, particularly in the distal colon. This increase was significant between five and 25 weeks. The results of these observations suggest that there is an adenoma-carcinoma sequence in this animal model. The value of scanning electron microscopy in identifying and quantifying the mucosal changes during carcinogenesis is emphasised.

The outlook for patients with colorectal carcinomas has not changed significantly over the last 20 years. ${ }^{1}$ This could be improved by the identification of individuals who have an increased susceptibility to colonic neoplasia, before the clinical manifestations of the disease becomes apparent. Those groups recognised to be at the highest risk include patients with multiple benign or malignant tumours of the colon, including the familial polyposis syndromes, and those with chronic inflammatory bowel disease.

The use of conventional biopsy and histology is of limited value in interpreting precancerous changes in the bowel; for example, the presence of inflammatory cells may interfere with the diagnosis of dysplasia in ulcerative colitis. ${ }^{2}$ Monitoring patients by means of circulating or tissue markers such as $\mathrm{CEA}^{34}$ has proven unreliable although their detection in colonic lavage may be more useful. ${ }^{5}$

\footnotetext{
Address for correspondence: Mr T Cooke. FRCS. Department of Surgery. Charing Cross Hospital, Fulham Palace Road, London W6.

Received for publication 2 September 1983
}

Conventional histology allows confirmation of the cellular basis for the surface changes but is a less reliable method of detecting the subtle early changes of colonic neoplasia compared with scanning electron microscopy (SEM). ${ }^{6}$

Cell proliferative changes, with an increase in the size of the crypt proliferative compartment have been observed in the colonic epithelium of patients with both polyposis coli $^{78}$ and ulcerative colitis. ${ }^{9}$ These changes have also been seen in the transitional mucosa adjacent to established carcinoma. ${ }^{10}$ This type of experimental study in man necessarily has to be restricted because of both practical and ethical constraints. Accordingly, animal models have been used to investigate the cytokinetic events which accompany neoplastic change.

In this investigation, we have induced colorectal neoplasia in rats using the cycasin derivative azoxymethane. Histologically this model closely mimics human colonic carcinoma. ${ }^{11}$ The precancerous changes have been studied morphologically in the weeks preceding the appearance of macroscopic 
tumours using conventional histology and scanning electron microscopy. At the same time, the colonic crypt cell kinetics were investigated using a stathmokinetic technique to derive the crypt cell production rate. ${ }^{12} 13$ The crypt cell production rate represents the efflux of cells from the proliferative to the functional compartment of the crypt.

We have attempted to determine whether morphological and cell kinetic changes of early neoplasia can be recognised before alterations noted on conventional microscopy. In addition, information regarding the presence of the adenomacarcinoma sequence in this model was sought.

\section{Methods}

\section{ANIMALS}

Male cob Wistar rats with an initial weight of $250 \mathrm{~g}$ were housed four to a cage. They were fed on a standard laboratory diet with free access to water. Carcinogenesis was induced by 12 weekly subcutaneous injections of azoxymethane $10 \mathrm{mg} / \mathrm{kg}$ body weight. Six groups of 10 rats were studied. The first group was killed five weeks after initial injection. Subsequent groups were killed at 10, 15, 20 , and 25 weeks. Negative controls included one untreated group, and one pair of saline injected rats for each time interval.

Morphological and kinetic experiments were performed on each of the groups of animals (see later). The rats were killed under deep ether anaesthesia and their colons removed. Each colon was opened longitudinally and washed with normal saline. Two $1 \mathrm{~cm}$ diameter samples were taken from five standard sites at equal intervals between rectum and caecum, one for morphology and one for crypt cell kinetics. For the morphological studies the tissue was fixed in $10 \%$ neutral buffered formol saline and in Carnoy's solution for the kinetic experiment.

\section{Morphology}

The five fixed samples of colonic mucosa from both rats in each group were prepared for scanning electron microscopy by postfixation in $2 \%$ osmium tetroxide for two hours. They were then washed in distilled water for five minutes and passed through a series of graded acetones to achieve dehydration. Critical point drying was carried out with liquid carbon dioxide. The specimens were mounted on aluminium slabs using silver conductive paint and gold palladium sputter coating was achieved using a Polaron E5100 sputter coating instrument. The biopsies were examined by a scanning electron microscope (JEOL JSM35) at an acceleration voltage of $20 \mathrm{kV}$.
Low power photomicrographs covering an area of $6.4 \mathrm{~cm}^{2}$ from each specimen were inspected to determine the number of microadenomas present and the number of crypts per adenoma. The area of each lesion was calculated using an Apple II microcomputer with digitising tablet and graphics software. Parallel samples of fixed mucosa were processed routinely into paraffin wax and strips of serial sections were stained with haematoxylin and eosin, and examined histologically for the presence of microadenomas.

\section{Crypt cell kinetics}

The groups of 10 animals were given an intraperitoneal injection of $1 \mathrm{mg} / \mathrm{kg}$ body weight of vincristine sulphate at $9.00 \mathrm{am}$. Rats were then killed at 15 minute intervals starting 30 minutes after injection. The effectiveness of the metaphase arresting agent at this dose was shown by the absence of postmitotic figures.

Each colon was treated as described above and the samples, fixed in Carnoy's solution, were stored in $75 \%$ alcohol. For measurement of the crypt cell production rate the tissue samples were rehydrated and hydrolysed in normal HCL for six minutes and stained by Feulgen's reaction using Schiffs reagent.

Individual crypts were microdissected and squashed under cover slips. The number of arrested metaphases counted in 10 crypts per sample were plotted against time. The crypt cell production rate was measured from the slope of this line using the method of least squares. Differences between crypt cell production rates were compared using a Student's $t$ test.

\section{Results}

Colonic tumours were found in all rats 25 weeks after initial azoxymethane injection, although occasional tumours were present by 20 weeks. At 25 weeks a total of 37 neoplasms were found in the group of 10 animals and were distributed predominantly in the distal colon (29 tumours). All but two of these lesions were invasive adenocarcinomas histologically.

SCANNING ELECTRON MICROSCOPIC APPEARANCES Normal colon

The scanning electron microscopic appearance of the normal rat colon varied from region to region. The mucosa of the distal colon was arranged in longitudinal folds (Fig. 1a), the crypt orifices being stellate in shape and uniform in size. In the transverse colon the epithelium was more flattened than in the distal colon, and was covered by mucous. The crypt orifices were regularly arranged although 

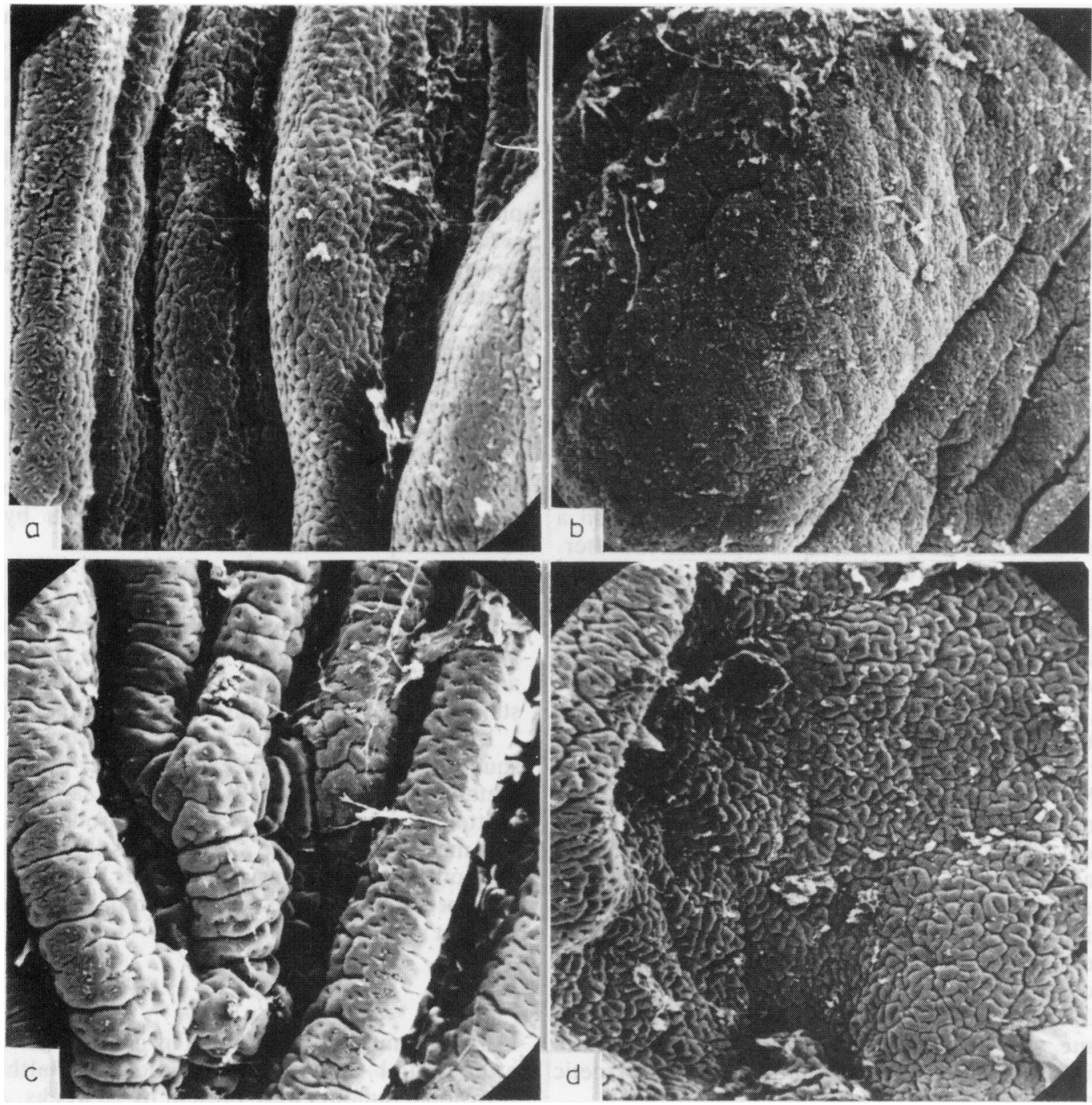

Fig. 1 Scanning electron microscopy appearances of normal mucosa: (a) descending colon, (b) transverse colon, (c) ascending colon, (d) caecum (scanning electron microscopy $\times 40$, original magnification).

more circular than the distal colon (Fig. 1b).

In the ascending colon crypts were less numerous and arranged over well marked mucosa folds (Fig. 1c). The surface of the caecum was flatter and the crypts surrounded by irregular sulci, an appearance reminiscent of cerebral cortex (Fig. 1d).

\section{Appearances during carcinogenesis}

The lesions appeared as raised foci centred on crypt orifices. The smallest involved a single crypt. but only those microadenomas involving at least two crypts were recorded (Fig. 2a). Most were seen in the distal colon and were present as early as five weeks and with increasing frequency after 15 weeks (Table 1). There was no significant difference between the number of lesions seen in the samples taken from the descending colon and the rectum.

With time the size of the lesions observed ('microadenomas') and the number of crypts per lesion increased and the crypt orifices became enlarged and slit-shaped (Fig. 2b, 2c, 2d). There was a statistically significant increase in the number of 

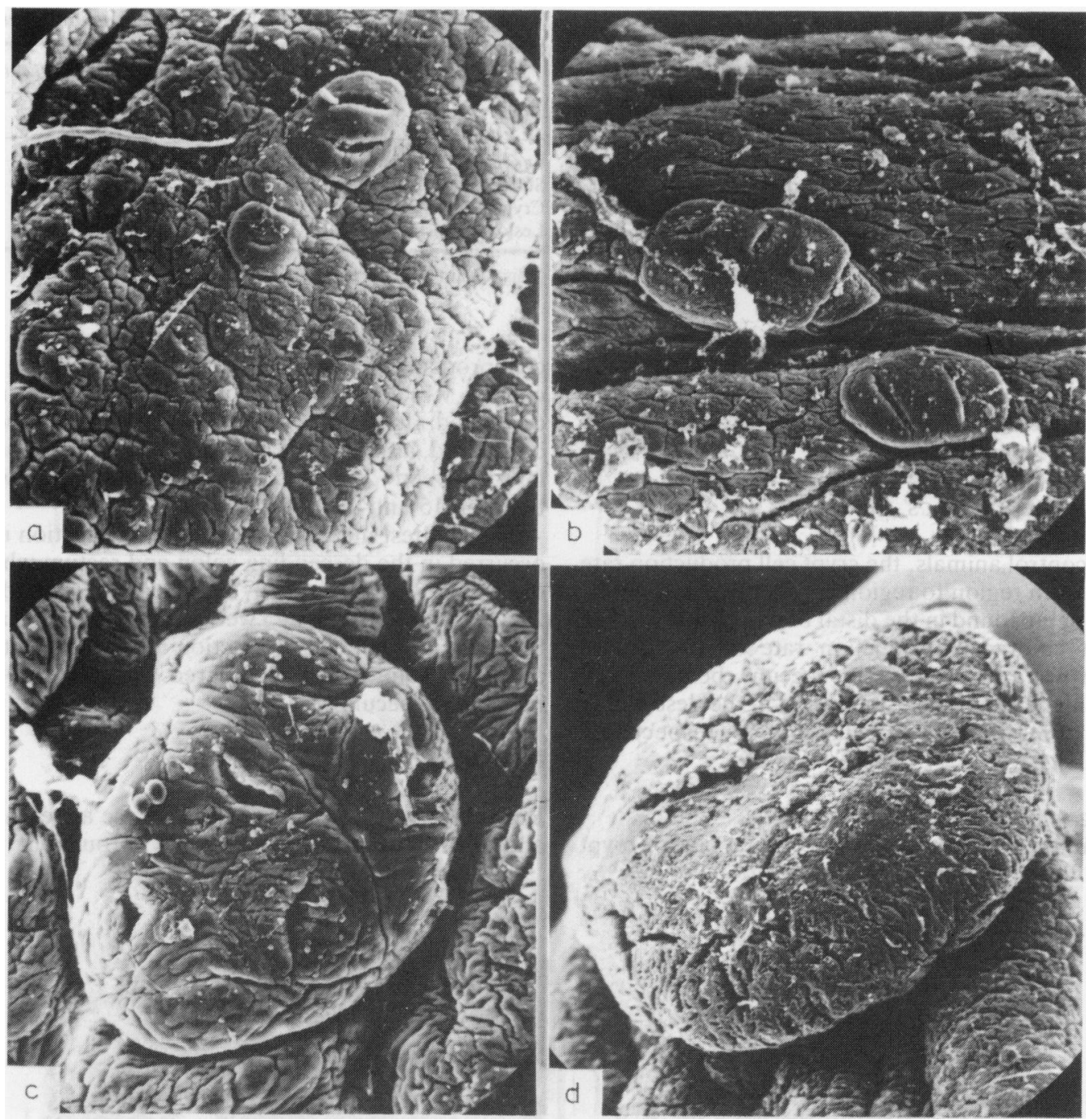

Fig. 2 Scanning electron microscopy appearances of microadenomas: (a) earliest lesion involving one and two crypts $\times 40$, (b) two and five crypt microadenomas $\times 100$, (c) polypoidal microadenoma $\times 240$, (d) polypoidal carcinoma $\times 20$ (all original magnifications).

lesions observed between five and 25 weeks $(\mathrm{p}<0 \cdot 001)$ and between 20 and 25 weeks $(\mathrm{p}<0 \cdot 05)$ (Table 2).

Histological examination showed that the early microadenomas . consisted of areas of dysplasia involving the upper portion of the crypt epithelium (Fig. 3a). At the later stage the process extended deeper down the crypts, and involved more crypts. producing sessile adenomas. Fewer lesions were noted in the sections examined histologically than in the portions of mucosa scanned by scanning electron microscopy. The sections did, however, sample a smaller area of mucosa.

The invasive tumours examined, with the exception of one signet-cell carcinoma, were all tubular and mucinous adenocarcinomas similar in appearance to typical human tumours (Fig. 3b).

At the cellular level changes were seen in both absorptive and mucous secreting cells. Compared with the normal appearance (Fig. 4a), there was a reduction in the height and the number of microvilli on the absorptive cells, and many were completely 
Table 1 Number of lesions per $6.4 \mathrm{~mm}^{2}$ field

\begin{tabular}{llllll}
\hline & \multicolumn{5}{c}{ Weeks after initial treatment } \\
\cline { 2 - 6 } & 5 & 10 & 15 & 20 & 25 \\
\hline Caccum & 0 & 0 & 0 & 1 & 1 \\
Ascending colon & 0 & 0 & 1 & 0 & 0 \\
Transverse colon & 0 & 0 & 3 & 5 & 8 \\
Descending colon and rectum & $3 \cdot 5$ & 5 & 6 & $9 \cdot 5$ & 13 \\
\hline
\end{tabular}

denuded of microvilli by 25 weeks (Fig. 4b). In the proximal colon the globular mucous secreting cells were reduced in number and were absent at 25 weeks.

\section{CRYPT CELL KINETICS \\ Normal colon}

In the control animals, the crypt cell production rate varied from region to region within the colon, lower values being found in the distal bowel (Table 3 ). The highest crypt cell production rate of $10 \cdot 23$ cells/ crypt $/ \mathrm{h}$ was observed in the caecum, being significantly higher than those measured in the descending colon, $6 \cdot 35$ and $5 \cdot 6$ cells/crypt/h respectively $(\mathrm{p}<0 \cdot() 1)$.

\section{During tumour induction}

After initial azoxymethane injection a rise of crypt
Table 2 Microadenomas in descending colon and rectum

\begin{tabular}{llllll}
\hline & \multicolumn{5}{c}{ Ceeks after initial treatment } \\
\cline { 2 - 6 } & 5 & 10 & 15 & 20 & 25 \\
\hline Lesions by SEM (no) & $3 \cdot 5^{*}$ & 5 & 6 & $9 \cdot 5$ & $13^{*}$ \\
Surfacc area of lesions & $2 \cdot 3$ & $2 \cdot 5$ & $2 \cdot 8$ & $2 \cdot 7$ & $3 \cdot 1$ \\
Crypts/lesions (no) & $2 \cdot 4$ & $3 \cdot 1$ & $2 \cdot 8$ & $3 \cdot 3$ & $3 \cdot 9$ \\
Lesions by histology (no) & 0 & 2 & 2 & 2 & 2 \\
\hline
\end{tabular}

* Significant increase in number of lesions $\mathrm{p}<0 \cdot(001$

cell production rate occurred in all areas of the colon, which increased with time. This rise continued after the course of carcinogen had been completed, although the increase was proportionally less between 20 and 25 weeks compared with between 15 and 20 weeks (Table 3 ).

The greatest increase in crypt cell production rate occurred in the descending colon and rectum where the values were statistically significantly elevated by 20 weeks $(\mathrm{p}<0 \cdot 01)$. By 25 weeks there was an 88 and $89 \%$ rise in crypt cell production rate in the rectum and descending colon, compared with only a $30 \%$ rise in the caecum.

\section{Discussion}

Both the scanning electron microscopic appearance and the crypt cell kinetics vary throughout the

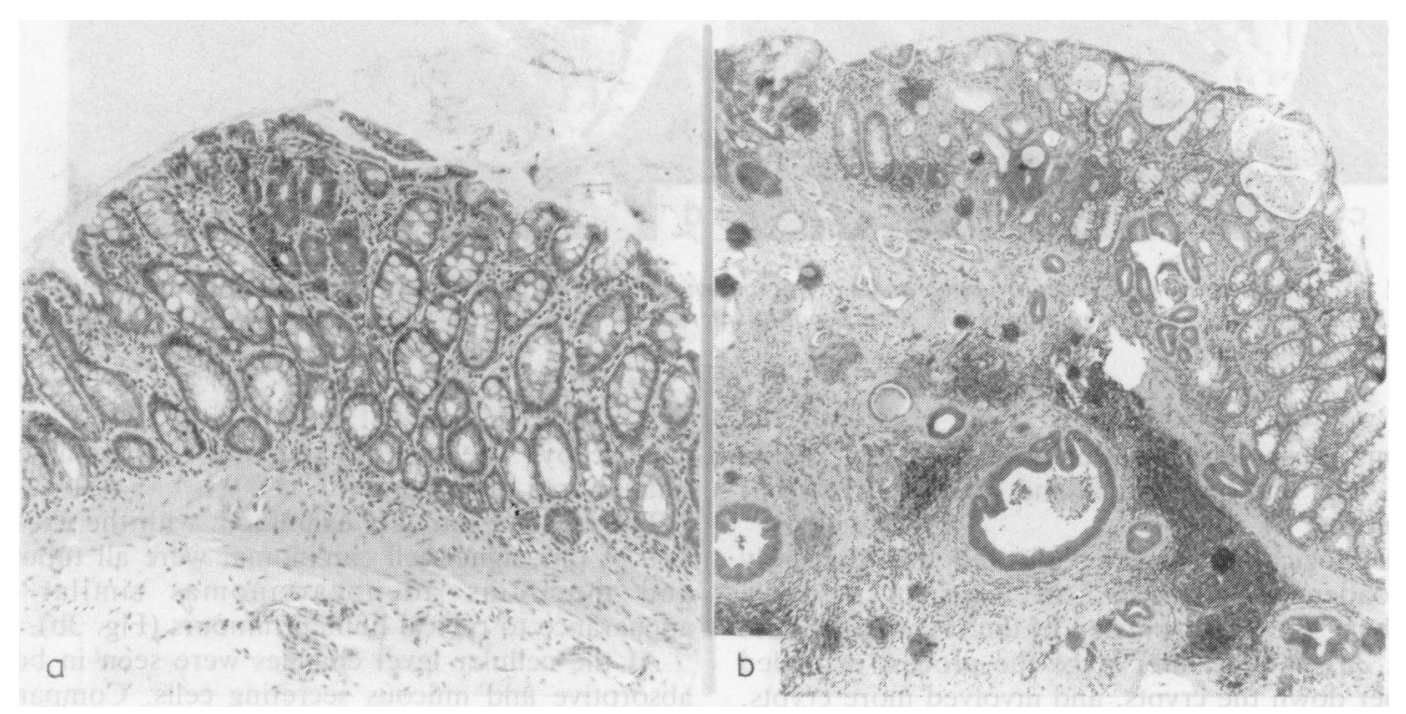

Fig. 3 Histological appearances of microadenomas: (a) typical section of an early microadenoma showing dysplastic epithelium in the involved crypts $H \& E \times 63$, (b) 25 week tumour showing submucosal invasion $H \& E \times 40$ (original magnifications). 

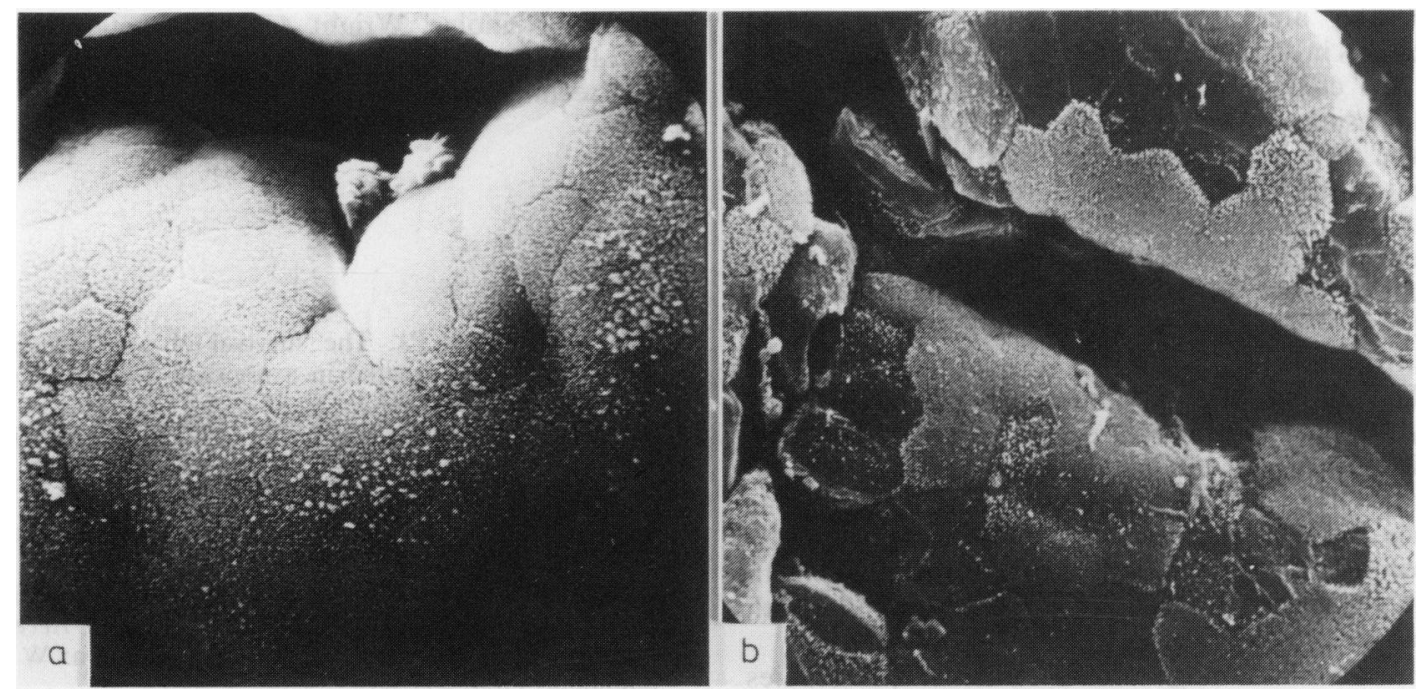

Fig. 4 Scanning electron microscopy appearances of crypt orifices: (a) normal caecal mucosa $\times 2000$, (b) Caecal mucosa after 25 weeks carcinogenesis. Individual epithelial cells are denuded of microvilli $\times 2000$ (original magnifications).

normal rat colon. The crypt cell production rate was highest in the caecum with lower values in the descending colon and rectum. Similar variations in crypt kinetics has been previously observed by Sunter. ${ }^{14}$ The mucosal pattern shown by scanning electron microscopy appears to reflect the underlying crypt cell population kinetics. The high crypt cell production rate seen in the caecum being associated with a more intricately folded mucosal pattern than the flatter epithelium of the distal bowel.

Since 1967 when Druckery introduced a series of chemical carcinogens derived from cycasin, which were extremely selective in the production of colonic neoplasia, detailed biological investigations

Table 3 Changes in CCPR during carcinogenesis

\begin{tabular}{|c|c|c|c|c|c|c|}
\hline \multirow[b]{2}{*}{$\begin{array}{l}\text { Area of } \\
\text { bowel }\end{array}$} & \multicolumn{6}{|c|}{ Changes in CCPR cells/crypt/h with time } \\
\hline & $\begin{array}{l}\text { Control } \\
\text { (no injec- } \\
\text { tion) }\end{array}$ & $\begin{array}{l}5 \\
\text { weeks }\end{array}$ & $\begin{array}{l}10 \\
\text { weeks }\end{array}$ & $\begin{array}{ll}15 & 20 \\
\text { weeks } & \text { weeks }\end{array}$ & $\begin{array}{l}25 \\
\text { weeks }\end{array}$ & $\begin{array}{l}\% \\
\text { change }\end{array}$ \\
\hline $\begin{array}{l}\text { Rectum } \\
\text { Descending }\end{array}$ & $6 \cdot 3+$ & $6 \cdot 84$ & $7 \cdot 56$ & $9 \cdot 01 \quad 11 \cdot 3^{*}$ & $12 \cdot() 1$ & 88 \\
\hline colon & $5 \cdot 6$ & 6.93 & $5 \cdot 11$ & $9.9^{*}$ & $11 \cdot 13$ & 89 \\
\hline Caccum & $10 \cdot 2+$ & $10 \cdot 2$ & $10 \cdot 4$ & $11 \cdot 04 \quad 12 \cdot(07$ & $13 \cdot 33$ & 30 \\
\hline
\end{tabular}

Regression coefficient varying between 0.89 and 0.98 .

* Significant increase in CCPR over control p<0.(01.

† Significant increase in CCPR between distal and proximal colon $\mathrm{p}<() \cdot() 1$. of carcinogenesis have become possible. ${ }^{15}$ In this study, we have observed changes in the crypt cell kinetics at an early stage of tumour induction which was mirrored by the disruption of the mucosal architecture. The alterations in crypt cell production rate and scanning electron microscopic appearance were observed before changes become apparent by conventional histology and light microscopy.

The most prominent feature of the precancerous colon was the development of microadenomas which increased in size and number during carcinogenesis and their presence gives some experimental support to the adenoma-carcinoma sequence. These neoplasms have not been noted in previous studies using similar experimental models ${ }^{116}$ and would easily be missed if histology alone was used. This shows the value of scanning electron microscopy in detecting focal as well as generalised abnormalities.

'Microadenomas' and established carcinomas were found almost exclusively in the distal colon. The initial crypt cell production rate was low in these areas when compared with the caecum, but the subsequent percentage rise in crypt cell production rate was much greater in those regions in which neoplasms developed. Although the alteration in crypt cell kinetics were induced initially by the carcinogen, the crypt cell production rate continued to rise 13 weeks after the last injection of azoxymethane.

Changes in colonic epithelial kinetics have been previously observed in this model by both thymidine 
labelling and stathmokinetic techniques. Most previous investigations, however, have concentrated on the changes in established carcinomas. ${ }^{11} 17$ In man, using in vitro thymidine labelling, an increase in the crypt proliferative zone has been detected in the transitional mucosa around colonic cancers. ${ }^{18}$ Changes in scanning electron microscopy have also been observed at the same site. ${ }^{9}$ The proliferative pattern is also disturbed in a similar fashion in patients with polyposis coli and chronic ulcerative colitis. ${ }^{19}$

The number of gross tumours visible microscopically does not reflect the true incidence of neoplastic lesions present in the colon in experimental carcinogenesis. The earliest neoplastic changes in colonic mucosa can be readily detected using the high resolution and great depth of field available with scanning electron microscopy even in patients with established colorectal cancer. ${ }^{20}$

Previous scanning electron microscopic studies have shown the territorial mozaic pattern of colonic mucosa. Each territory encompasses several crypts. This pattern is lost in adenomas ${ }^{21}$ which also show distorted crypt mouths ${ }^{22}$ and irregularly arranged epithelial cells. ${ }^{2.3}$ Changes are seen as early as five weeks after exposure to carcinogen and tumours may be seen after 16 weeks. ${ }^{2+25}$

In the rat model it has been suggested that tumours arise de novo in flat mucosa, without an intervening polyp stage. ${ }^{26}$ We have shown that the earliest neoplastic changes, involving as few as one or two crypts, can be readily shown by scanning electron microscopy and that there is a progressive increase in size of microadenomas with similar surface morphology, leading to the production of invasive carcinomas. As carcinogenesis proceeds the crypt mouths become enlarged and distorted in appearance.

Histological examination of the gross tumours confirms that the end result of the progression which includes the early dysplastic lesion and the later sessile adenoma, is a series of invasive tubular and mucinous and signet-cell adenocarcinomas ${ }^{27}$ which closely resemble the lesions seen in human colonic neoplasia.

In conclusion, evidence is presented to support the view that scanning electron microscopy is of value in recognising early preneoplastic changes of colorectal cancer and that corresponding changes in cell kinetics occur. These observations also suggest that there is an adenoma-carcinoma sequence in this animal model.

This investigation was supported by a grant from the British Medical Association. We would like to thank
Professor Nicholas Wright (Royal Postgraduate Medical School) for his guidance with the cell kinetic techniques.

\section{References}

1 Gill PG, Morris PJ. The survival of patients with colorectal cancer treated in a regional hospital. $\mathrm{Br} J$ Surg 1978; 65: 17.

2 Morson BC. Rectal biopsy in inflammatory bowel disease. N Engl J Med 1972; 287: 1337-9.

3 Isaacson P. Judd MA. Immunohistochemistry of carcinoembryonic antigen in the small intestine. Cancer 1978; 42: 1554-9.

4 Neville AM, Laurence DJR. Tumour markers and the gastrointestinal tract. In: Wright $\mathrm{R}$, ed. Recent advances in gastrointestinal pathology. London: W B Saunders, 1980: 255-66.

5 Poleski MH, Blattner WA, Chatt M. CEA in colonic lavage of individuals at high risk of large bowel cancer. Gastroenterology 1978; 74: 1140.

6 Shamsuddin AKM. Trump BF. Colon epithelium. II. In vivo studies of colon carcionogenesis. Light microscopic, histochemical and ultrastructural studies of histogenesis of azoxymethane-induced colon carcinomas in Fischer 344 rats. J Natl Cancer Inst 1981; 66: $389-401$.

7 Bleiberg H, Mainguet $\mathrm{P}$, Galand $\mathrm{P}$. Cell renewal in familial polyposis. Comparison between polyps and adjacent healthy mucosa. Gastroenterology 1972, 63: 240-5.

8 Lipkin M. Growth kinetics of normal and premalignant gastrointestinal epithelium. In: Growth kinetics and biochemical regulation of normal and malignant cells. Baltimore: Williams and Wilkins, 1977: $562-89$

9 Eastwood GL. Trier JS. Epithelial cell renewal in cultured rectal biopsies in ulcerative colitis. Gastroenterology 1973; 64: 383-90.

10 Maskers AP, Deschner EE. Tritriated thymidine incorporation into epithelial cells of normal appearing colorectal mucosa of cancer patients. $J$ Natl Cancer Inst 1977; 58: 1221-4.

11 Sunter JP. Experimental carcinogenesis and cancer in the rodent gut. In: Appleton DR. Sunter JP. Watson $\mathrm{AJ}$, eds. Cell proliferation in the gastrointestinal tract. London: Pitman Medical, 1980): 255-77.

12 Clarke RM. A comparison of metaphase arresting agents and tritriated thymidine autoradiography in the measurement of the site of entry of cells into mitosis in the crypts of Lieberkühn of the rat. Cell Tissue Kinet 1971: 4: 263-72.

13 Wright NA, Appleton DR. The metaphase arrest technique. A critical review. Cell Tissue Kinet 1980; 13: 643-63.

14 Sunter JP. Wright NA. Appleton DR. Cell population kinetics in the epithelium of the colon of the male rat. Virchow's Arch [Cell Pathol] 1978; 26: 275-87. 
15 Druckery H. Production of colonic carcinomas by 1,2-dialkylhydrazines and azoxyalkines. In: Burdettc JW, ed. Carcinoma of the colon and antecedent epithelium. Springfield, Illinois: Thomas, 1970): 367-79.

16 Maskens AP, Dujardin-Loits RM. Experimental adenomas and carcinoma in the large intestine behave as distinct entities: most carcinomas arise de novo in flat mucosa. Cancer 1981; 47: 81-9.

17 Deschner EE. Experimentally induced cancer of the colon. Cancer 1974; 34: 824-8.

18 Riddell RH, Levin B. Ultrastructure of the transitional mucosa adjacent to large bowel carcinoma. Cancer 1977; 40: 2509-22.

19 Camplejohn RS, Bone U, Aherne W. Cell proliferation in rectal carcinoma and rectal mucosa. A stathmokinetic study. Eur J Cancer 1973; 9: 577-81.

20) Traynor OJ, Costa NL, Blumgart LH, Wood CB. A scanning electron microscopy study of ultrastructural changes in the colonic mucosa of patients with large bowel tumours. Br J Surg 1981: 68: 701-4.

21 Fenoglio CM. Richart RM. Kaye GI. Comparative electron microscopic features of normal, hyperplastic. and adenomatous human colonic epithelium. Gastro- enterology 1975; 69: 10(1)-9.

22 Toth B, Malick C. Production of intestinal and other tumours by 1,2-dimethylhydrazine dihydrochloride in mice. II. Scanning electron microscopic and cytochemical study of colonic neoplasms. Br J Exp Pathol 1976; 57: 696-705.

23 Barkla DH, Tutton JM. Surface changes in the descending colon of rats treated with dimethylhydrazine. Cancer Res 1977: 37: 262-71.

24 Carachi R, Busuttil A, Joffe SN, Blumgart LH. Multiple polyps and colonic neoplasia induced in the rat. J Surg Res 1980; 29: 363-70.

25 Sunter JP, Appleton DR, Wright NA. W/atson AJ. Pathological features of the colonic tumours induced in rats by the administration of 1,2 dimethylhydrazine. Virchows Arch /Cell Pathol] 1978; 29: 211-33.

26 Maskens AP. Dujardin-Loits RM. Experimental adenomas and carcinomas of the large intestine behave as distinct entities: most carcinomas arise de novo in flat mucosa. Cancer 1981: 47: 81-9.

27 Bonello JC, Sternberg SS, Quan SH. The significance of the signet-cell variety of adeno-carcinoma of the rectum. Dis Colon Rectum 1980; 23: 180-3. 